\title{
Enunciación
}

http://revistas.udistrital.edu.co/ojs/index.php/enunc

DOI: http://doi.org/10.14483/22486798.12732

REPORTE DE CASO

\section{De la asignatura al taller de literatura como estrategia didáctica}

\author{
From the subject to the literature workshop as a didactic strategy \\ Yesny Milena Triana Castro*
}

\section{Resumen}

Este artículo es el resultado de una intervención pedagógica realizada en la Escuela Normal Superior Distrital María Montessori (ENSDMM) de Bogotá, D.C., con estudiantes de grado undécimo durante el segundo semestre de 2015 en el marco de un proyecto de aula titulado "Ritos y rituales, un viaje por el mundo a través de la literatura universal", en el que participó un equipo de maestros en formación de la Licenciatura en Educación Básica con énfasis en Humanidades y Lengua Castellana de la Universidad Distrital Francisco José de Caldas. El trabajo confirma como problema la necesidad de movilizar la concepción de asignatura de español como punto donde se imparten saberes acerca de la lengua y la literatura, al de taller literario, como espacio para la creación colectiva y la reflexión crítica conjunta. Se evidencia entonces, una propuesta para la mejora de la enseñanza de la literatura, en la que se presenta, en orden, el diseño del taller de literatura, la importancia de un enfoque curricular y la sistematización de la experiencia del maestro en formación. Se concluye que el taller literario puede llegar a reemplazar varios componentes de la asignatura de español ya que efectivamente permite la construcción de conocimiento tanto del maestro como del estudiante.

Palabras clave: literatura, currículo, práctica pedagógica, estrategia de enseñanza, taller.

\begin{abstract}
This article is the result of a pedagogical intervention carried out in the Maria Montessori Superior Normal School (ENSDMM) of Bogotá, DC, with undergraduate students during the second semester of 2015 within the framework of a classroom project entitled "Rites and rituals, a journey through the world through universal literature ", in which a team of teachers participated in the formation of the Bachelor in Basic Education with an emphasis in Humanities and Spanish Language of the Francisco José de Caldas District University The work confirms as a problem the need to mobilize the conception of the subject of Spanish as a point where knowledge about language and literature is imparted, literary workshop as a space for collective creation and joint critical reflection. It is then evident, a proposal for the improvement of the teaching of literature, presenting in order the design of the literature workshop, the importance of a curricular approach and the systematization of the experience of the teacher in training. It is concluded that the literary workshop can replace several components of the subject of Spanish since it effectively allows the construction of knowledge of both the teacher and the student.
\end{abstract}

Keywords: literature, curriculum, pedagogical practice, teaching strategy, workshop.

\footnotetext{
Licenciada en Educación Básica con énfasis en Humanidades y Lengua Castellana de la Universidad Distrital Francisco José de Caldas (Colombia). Docente de Lengua Castellana en el Colegio de Bachillerato Niño Jesús en Soacha (Cundinamarca, Colombia). Correo electrónico: miletrica13@ hotmail.com - ORCID: https://orcid.org/0000-0001-8121-3929
}

Cómo citar este artículo: Triana Castro, Y.M. (2018). De la asignatura al taller de literatura como estrategia didáctica. Una reflexión desde la práctica docente. Enunciación, 23(2), 225-236. DOI: http://doi.org/10.14483/22486798.12732 Artículo recibido: 15 de noviembre de 2017; aprobado: 08 de agosto de 2018 


\section{Introducción}

Las facultades de educación cumplen un papel fundamental en la transformación de la práctica docente y en la resignificación de un nuevo proyecto educativo del país, a través de las propuestas de práctica pedagógica que realizan los aspirantes a licenciados en las instituciones educativas de preescolar, básica secundaria y media; además, en las Escuelas Normales Superiores donde también se forman los fututos maestros para la infancia. En este sentido, se propone aunar esfuerzos entre coordinadores de práctica docente de las facultades de educación y de las Normales Superiores, y estos a su vez, con los maestros titulares o de aula y aquellos en formación, con el fin de plantear intervenciones pedagógicas que favorezcan a la comunidad educativa y redunden en la cualificación de las prácticas de enseñanza, en este caso, de la literatura.

En el presente artículo se considera esta condición y se plantea una propuesta a través del diseño, implementación y evaluación de una secuencia de talleres literarios que dieron vida al proyecto "Ritos y rituales, un viaje por el mundo a través de la literatura universal", el cual se desarrolló con 160 estudiantes de grado undécimo en el espacio académico denominado: "Taller de Literatura II".

Sobre una investigación cualitativa, se acudió al análisis documental, cuyos resultados se triangularon en una matriz a partir de los presupuestos conceptuales, pedagógicos y didácticos que subyacen tanto en la secuencia de cinco talleres desarrollados durante un semestre, como en el Proyecto Educativo Institucional de la Escuela Normal Superior María Montessori (ENSDMM) y el registro de los diarios de campo. Este análisis contrastivo tuvo en cuenta tres categorías: 1) la intención formativa del taller literario, 2) el lugar del currículo y 3) la reflexión sobre la práctica docente investigativa.

\section{La intención formativa del taller literario}

Situados en una perspectiva dialógica de la literatura y de su intención estética en particular (Bajtín, 1982), se aborda la enseñanza de la literatura desde una intención formativa, lo cual condujo a optar por la estrategia didáctica del taller literario y del cual se nombran algunas características teóricas, para luego encontrar el sentido y las bases de la experiencia descrita más adelante.

Antes de ello, se toma un espacio para considerar el papel de la literatura en la educación y cómo el taller literario puede asumir la responsabilidad de su verdadera enseñanza. Así las cosas, la literatura se ha asumido como instrumento fundamental, pues atrapa específicamente a estudiantes que se han apartado de la lectura y al mismo tiempo desconocen hasta el propio lenguaje que los rodea para escribirlo. Entonces, los que experimentan en la escuela -sobre todo los profesores- han intentado nuevas formas para que este conocimiento forme parte de la enseñanza, en búsqueda de la transformación y de la asimilación de la realidad que se camufla en otras dimensiones. Para eso, es deber separar:

[...] el valor del término enseñanza de las concepciones convencionales o tradicionales y otorgarle más bien un valor fenoménico; es decir, inscribirlo en el mundo de la vida de los sujetos históricos. En este punto se descubrirá, con cierta sorpresa, que enseñar -en el caso de la literatura, al menos- comparte una afinidad innegable con actividades como deleitar, provocar, jugar, engañar, desengañar, confundir, inventar, reinventar, estructurar, desestructurar, transformar, interrogar, inquietar $y$, de seguro, muchos más que pueden encontrarse. (Guevara, 2015, p. 12)

Lo que quiere decir que enseñar literatura es reconocer que como una parte más del ser humano, debe ser una actividad que genera acciones novedosas, que no caen en el típico juego de que la enseñanza se trata de mera instrucción para adaptar al joven a cualquier tipo de conocimiento. Significa entonces que, dentro de estas acciones recíprocas y creativas, el papel del maestro no es superior al del estudiante, pues esta persona tiene que brindar desde su experiencia, los instrumentos dignos para la lectura y la escritura para luego atraer el 
interés de su seguidor, es decir, "enseñar literatura equivale fenoménicamente a recrear los acontecimientos cotidianos con la pluma del maestro que escribe sobre sus experiencias más simples y coloquiales y las comparte leyéndolas a los niños, para que luego ellos puedan imitarlo" (Guevara, 2015, p. 15), siempre respetando el error y construyendo aprendizajes conjuntamente.

Sin embargo, no es suficiente pensar que esta enseñanza es cómoda o que es un solo paso el decir del hacer; en realidad requiere de múltiples esfuerzos, pero antes que nada, de una verdadera vocación: si el docente no ama el escenario significativo que está creando, simplemente este carecerá de fuerza con rapidez. Para ello además necesita de un claro propósito, es decir, ¿qué busca alcanzar con lo que enseña?, y en esta línea preguntarse a través de qué formas lo va a lograr.

Una de esas formas, que logra una verdadera enseñanza de la literatura, es el taller literario, por cuanto permite fortalecer las capacidades interpretativas, comunicativas y propositivas de los estudiantes en la recreación con diversos mundos ofrecidos por las narraciones literarias. Es una propuesta novedosa que se ajusta a la necesidad de despertar la participación, discusión e interacción de los niños y jóvenes, ya que, en palabras de María Elvira Rodríguez Luna (2012) "permite la reflexión sobre las acciones propias y ajenas, facilita la relación entre pares, promueve la construcción compartida de conocimientos, así como la anticipación para dar solución a los problemas que emergen en el diálogo entre los participantes" (p. 25). En otras palabras, el taller de literatura funciona como una táctica de intervención activa en donde se desarroIla la producción discursiva de cada participante, todos aprenden en una atención recíproca y se da lugar a varias interpretaciones y sentidos.

Por supuesto, acercar a los estudiantes a la vivencia de la literatura mediante el taller literario posibilita buscar alternativas pedagógicas menos unidireccionales, como aquellas donde el docente es quien transmite sus conocimientos teóricos y el estudiante recupera la información superficial de las obras; además, es el adulto, en este caso, quien tiene el significado verdadero de cada historia y no permite que el niño exponga su punto de vista, pues su intervención no tiene valor. Se opta, entonces, por una perspectiva más dialógica que favorezca la intersubjetividad y ponga la palabra al servicio de la construcción conjunta de saberes y experiencias.

De esta manera, el taller crea un ambiente específico para que el guía (docente) y el artesano (estudiante) se sientan a gusto en su hacer, pero como en todo taller, los participantes trabajan en conjunto, se benefician unos con otros, porque tienen el mismo propósito; el taller es un espacio "para crear y asentar hábitos, para arraigar rutinas, para aclimatar métodos, para ir propiciando la familiaridad y la confianza en el oficio" (Vásquez, 2006 , p. 34). Es una estrategia que siempre busca la formación de todo el que participe pues alejándose de las formas tradicionales, incluye en su intención motivar y atraer el aprendizaje.

Por tanto, el taller de literatura puede ser más provechoso que la asignatura de lengua castellana, pues en esta última solo se ha limitado a transmitir por medio de contenidos los conceptos de los elementos lingüísticos, a pedir que se señalen las categorías gramaticales en la oración, a leer por obligación, a aprender de memoria biografías de autores, a hacer planas por errores ortográficos o a explicar que existe un emisor y un receptor, que si bien son necesarios y se han buscado estrategias creativas para profundizar en ellos, sus vacíos en el reconocimiento y práctica del estudiante son evidentes, precisamente porque falta integrar actividades del taller que son:

[...] intencionalmente planeadas con el propósito de promover la participación de los miembros del colectivo, la producción de textos orales con sentido, las actividades del lenguaje articuladas al desarrollo del currículo y los procesos de autoformación e interlocución a través del acompañamiento de un observador participante. (Rodríguez, 2012, p. 16) 
A partir de estos supuestos teóricos, se dio vía a la secuencia de talleres literarios realizados, en el marco del proyecto de aula titulado "Ritos y rituales, un viaje por el mundo a través de la literatura universal", el cual se fundamentó en cómo algunos ritos y rituales eran llevados a cabo en determinados lugares del mundo y cómo esas acciones humanas eran representadas en algunas obras literarias. El pretexto para acercar a los estudiantes a la literatura fue el estudio del rito $y$ ritual en la obra literaria, pues estas son actividades significativas de la realidad del hombre que han sido percibidas y narradas tanto en prosa como lírica; también, demuestran que la escritura se manifiesta en diversos lugares del mundo, en distintas lenguas y lenguajes, y son recopiladas para dilucidar múltiples interpretaciones que se pueden hallar en la palabra; más allá de ser manifestaciones del espíritu, representan los acontecimientos que padece el ser humano a través de un expresar estético-creativo, en el que intervienen los sentimientos no solo de un autor, sino de un pueblo o de una época.

El proyecto tuvo como propósito brindar las herramientas necesarias para comprender e interpretar ese mundo literario que rodea a los estudiantes de educación media y que desde varias partes no es ajeno a su lectura e imaginación. De igual manera, tuvo en cuenta que la lectura y la escritura son categorías que permiten comprender de varias formas la realidad, que la literatura, como arte que se manifiesta en ellas, es un mundo de palabras que obedece a la armonía o a la liberación de los pensamientos y que admite ampliar las cualidades formativas ya sean estéticas, cognitivas, afectivas o lingüísticas.

\section{El lugar del currículo}

El taller literario como estrategia didáctica para la enseñanza de la literatura debe asumir primeramente varios retos relacionados con la parte organizacional de la educación nacional, pues como forma que pueda reemplazar a la asignatura de lengua castellana, no los puede evadir. En el caso colombiano, se refiere al seguimiento de los Lineamientos y estándares curriculares, pues la estructura u organización que advierte el Ministerio de Educación del país participa de forma activa en toda institución y constituyen casi toda la base del programa educativo. Los lineamientos curriculares ${ }^{1}$ buscan orientar los currículos de cada saber, teniendo en cuenta que los educandos tienen diversas edades y los tiempos van cambiando, se fundamentan en que:

El papel que cumplen las áreas y las disciplinas en los currículos de la educación básica y media, varía según las épocas y las culturas. A los educadores especialistas corresponde elaborar y asumir los programas curriculares como transitorios, como hipótesis de trabajo que evolucionan a medida que la práctica señala aspectos que se deben modificar, resignificar, suprimir o incluir. (MEN, 2014, p. 3)

En esta línea, para Grundy (1994), el currículo no es un concepto abstracto, sino una construcción cultural que demuestra las formas de organizar el conjunto de prácticas educativas, el currículo no se encuentra en la estantería del profesor, sino en las acciones de las personas inmersas en la educación; en pocas palabras, no se crea un currículo con conjeturas, sino con el conocimiento del contexto de la institución. En Colombia el currículo es definido por la Ley 115 de 1994 como:

El conjunto de criterios, planes de estudio, programas, metodologías y procesos que contribuyen a la formación integral y a la construcción de la identidad cultural nacional, regional y local, incluyendo también los recursos humanos, académicos y físicos para poner en práctica las políticas y llevar a cabo el proyecto educativo institucional. (art. 76)

1 Son las orientaciones epistemológicas, pedagógicas y curriculares que define el MEN con el apoyo de la comunidad académica educativa para apoyar el proceso de fundamentación y planeación de las áreas obligatorias y fundamentales definidas por la Ley General de Educación en su artículo 23 (Ministerio de Educación Nacional, 2014). 
Por tanto, es casi un deber su ejercicio en las instituciones educativas por parte del Estado y del Ministerio de Educación Nacional, y de esta manera, es considerado como el conjunto que reúne el plan de estudios, las temáticas, metodologías y procesos que deben seguir los maestros para la enseñanza de determinada asignatura durante cada año escolar.

En cuanto a la enseñanza y el aprendizaje de la literatura, el currículo es el que especifica los contenidos y temáticas a trabajar en cada grado, con relación a los movimientos, teorías y autores literarios que influenciaron en cada país según la época, además de explicar la metodología que el docente debe seguir, para que, en vez de lograr una interpretación profunda de los textos, haga que el niño o joven se memorice los estilos de cada autor, sus obras, el contexto histórico, temas, etc. En consecuencia, la lectura, la escritura y la literatura necesitan una mayor atención, pues es común escuchar que en las últimas décadas ya no se lee; la escritura tiene demasiados límites; la vieja literatura es aburrida, y las reglas de saberes y comportamiento se han perdido. ¿Será este un problema de los estudiantes o más bien del sistema educativo que se rige bajo el tradicional currículo?

Esto quiere decir que el proyecto "Ritos y rituales, un viaje por el mundo a través de la literatura universal", desde los principios de la institución y sin descartar algunos de los Lineamientos y estándares del lenguaje, recurrió a un currículo que asumiera la literatura como una forma dinámica que tuviera en cuenta el vivir o accionar de los estudiantes y sus relaciones con los demás en determinado contexto, tiempo y modo. Esto visto, tanto en la etapa teórica como práctica, pues el estudio, observación y vivencia de cada uno de los rituales, dinamizaba la manera de aprender significativamente y de relacionar la lectura con las mismas acciones humanas; además, el estudiante puso a prueba su expresión oral, corporal y literaria por medio de la lectura crítica y de la producción escrita. En fin, los estudiantes actuaron como ciudadanos críticos de una realidad y no como meros repetidores de contenidos teóricos o de lecturas que se olvidan a corto tiempo.

De esta manera, se propone crear un currículo no fragmentado, que no divida cada área del conocimiento, sino que en unidad se aparte de los mecanismos tradicionales de enseñanza; que tenga en cuenta que el hombre es un ser social y que en la escuela más que necesitar unos contenidos específicos en una asignatura, se debe construir un conjunto de formas emancipadoras, en donde los docentes junto a sus estudiantes puedan pensar y actuar en la transformación de los métodos que impiden el verdadero aprendizaje. Esto no significa eliminar el currículo ya establecido; el docente como guía puede adaptarlo de manera que cumpla con los objetivos y elementos del taller, que lo hacen más dinámico y, sobre todo, una construcción social y cultural.

Este proyecto bajo la ejecución del taller literario se ajustó a esta iniciativa y tuvo en cuenta que el currículo actúa según la vida y contexto de los estudiantes, pues es el interés que forma parte del placer de aprender el que los direcciona a adquirir conocimientos y a re-significar la realidad.

\section{La reflexión sobre la práctica docente investigativa}

Se sabe que la escuela es un campo que permite perfectamente observar, aplicar y comprobar a través de la investigación; por tanto, arriesgarse a llevar a cabo el taller literario es el papel que asume el maestro como investigador, para reflexionar sobre las necesidades y los avances por la mejora de la enseñanza de la literatura. La experiencia que se describe más adelante camina por esta línea y fue realizada por docentes en formación, por ello es importante sustentar teóricamente cómo influyen estos procesos pedagógicos durante esta etapa de preparación.

Teniendo en cuenta que la práctica docente es un camino para la construcción del profesionalismo, que en su labor y análisis va adquiriendo y fortaleciendo conocimientos pedagógicos, todo 
docente o maestro debe reflexionar sobre su accionar en el proceso de la enseñanza, pues esto permite crear concepciones innovadoras sobre lo que es conveniente hacer para la transformación de la educación: significa examinar las necesidades, los avances y los quiebres en la enseñanza.

Así como el maestro en ejercicio realiza una retroalimentación de su labor, el maestro en formación con mayor responsabilidad lo debe hacer, ya que son ellos claros investigadores que desde una o varias problemáticas, identifican la función de los procesos pedagógicos y de acuerdo con estas, fijan debidas transformaciones. Para ello, deben considerar que la práctica docente es un proceso de evolución que se da por la interacción con los otros (estudiantes, superiores, colegas), por las experiencias vividas en la clase y cuando logra criticar y con más fuerza autocriticarse:

Necesita de materiales, de estrategias, de instrumentos y de protocolos para sistematizar los distintos pasos y momentos del ciclo reflexivo. Esta práctica es un aspecto más de este constructo, como momento de interrelación entre los referentes teóricos, las propuestas didácticas y sus estilos docentes. (Masgrau y Falgas, 2013, p. 113)

En este sentido, observar la práctica docente dentro de la literatura es la oportunidad para la reflexión constante de la pedagogía del lenguaje a través de la interacción y la acción con los estudiantes y el contexto, sobre todo porque el docente en formación divisa el desarrollo de la capacidad discursiva que va adquiriendo en sus relaciones orales y comunicativas, no solo en el vaivén del diálogo, sino en su propia experiencia como aprendiz, pues pasa de:

[...] una práctica idealizada en el intercambio continuo de puntos de vista, sentimientos e ideas acordes con determinada situación comunicativa, a una práctica vivencial capaz de aprender y enseñar el uso equitativo de la palabra como reconocimiento de la validez de condiciones para el interlocutor, de propiciar asumir de manera razonada el disenso o el acuerdo como declaración de una escucha comprensiva, y propender por el desarrollo de una conciencia cada vez más crítica y transformadora en contextos de diversidad. (Gutiérrez, 2016)

De esta manera, el docente en formación dentro del taller literario logra potenciar sus capacidades orales y comunicativas, gracias a la interacción que tiene con los niños y jóvenes, el contexto, las obras, con los pensamientos críticos de otros, la vivencia de las acciones humanas narradas y con sus capacidades cognitivas y argumentativas. Así las cosas, la reflexión de los maestros en formación en torno al proyecto realizado, puede constar su experiencia, la manera como fortalecieron sus capacidades discursivas y la funcionalidad de un proyecto en equipo de la siguiente manera:

\section{Etapas y resultado de la propuesta de intervención}

Cabe aclarar que antes de iniciar el proyecto, el cuerpo de personas encargadas se reunió para diseñar cada una de las etapas y momentos, así como de escoger los textos, los ritos y rituales y las obras literarias posibles para leer, por ejemplo la obra de Martine Segalen (1998), Ritos y rituales contemporáneos, el rito del té británico, evidenciado en el séptimo capítulo, "Una merienda de locos", de Alicia en el país de las Maravillas, de Lewis Carroll (1865), el rito del día de los muertos en México, evidenciado en "Todos santos, día de muertos", de la obra de Octavio Paz (1950), El laberinto de la soledad. Durante el proceso se socializaba el trabajo y según las necesidades presentadas u opiniones de los estudiantes, se integraban nuevos conceptos u obras o se cambiaban según lo acordado.

Durante las prácticas se hizo uso de varios instrumentos que sirvieron como herramientas útiles del taller y para la ejecución de los productos, desde material físico como: libros, folletos, carteleras, vestuario, alimentos, etc., hasta material audiovisual como: videos de los rituales, música, películas 
o información de internet. Siempre se establecieron ambientes adecuados según el momento que se realizaría, por ejemplo, si se llevaba a cabo una lectura comentada, los estudiantes creaban un círculo para la discusión; si se iba a observar algún video o puesta en escena de los ritos, se adecuaba el auditorio de la ENSDMM o espacios externos como la cancha, la cafetería, el aula de clases, la zona verde o el salón de danzas. Tanto docentes como estudiantes siempre prestaban gran interés por las sesiones, pues salían del contexto tradicional de una clase a experimentar la literatura de otra forma más significativa, con sonidos, olores, colores, sabores y, sobre todo, construyendo en conjunto los conocimientos por medio de la interacción, de la lectura en voz alta, de la lectura dramática y de la exposición oral de sus interpretaciones y pensamientos.

De esta manera, el proyecto se estructuró en tres etapas: profundización, recreación y reflexión, las cuales mantuvieron siempre una estrecha relación entre la teoría y la práctica.

En la primera etapa, denominada profundización, se realizó la retroalimentación conceptual de rito, ritual y algunas pautas de análisis de un rito, teniendo en cuenta la propuesta teórica de Martine Segalen y la cual buscaba brindar las bases cognitivas en los estudiantes para su participación en las otras etapas; de igual forma, los estudiantes junto a los docentes trabajaron los postulados de varios autores sobre la literatura, el rito y ritual, evidenciándose cómo los estudiantes apropiaban opiniones, reflexiones y conocimientos tanto de sus docentes, como de sus pares. Durante esta etapa, se realizaron lecturas comentadas sobre los conceptos básicos de literatura, rito y ritual que se iban a trabajar durante todo el semestre, se escucharon voces de diversos autores y cada uno creó sus propios significados. Esto, tomando el taller como fuente dialógica y participativa, en donde los presentes intercambian conocimientos y expresan sus opiniones sin ser intervenidos o mesurados por el docente, pues cabe recordar lo dicho por María Elvira Rodríguez (2012):
La incorporación del diálogo como acción discursiva en el aula involucra el reconocimiento de los turnos, la necesidad de escuchar y de mantener la coherencia temática para el logro de los propósitos comunicativos, teniendo en cuenta no solamente las estructuras lingüísticas y las secuencias para construir relaciones lógicas, sino también las acciones que se desencadenan a través de la palabra. (p. 22)

En la asignatura de lengua castellana son pocos los momentos oportunos para la participación, pues por el mismo tiempo, el afán por cumplir con todos los desempeños y temáticas, la necesidad de evaluar o la imposición de lecturas, el estudiante no desarrolla su discurso ni materializa sus opiniones si se encuentra en un vaivén de conocimientos que no ha alcanzado significativamente. En el taller de literatura en cambio, mientras se socializa y discute un texto de manera profunda, fortalece su capacidad argumentativa, sus relaciones con los demás, su aprendizaje y puede integrar en el proceso elementos sintácticos, semánticos, pragmáticos y gramaticales.

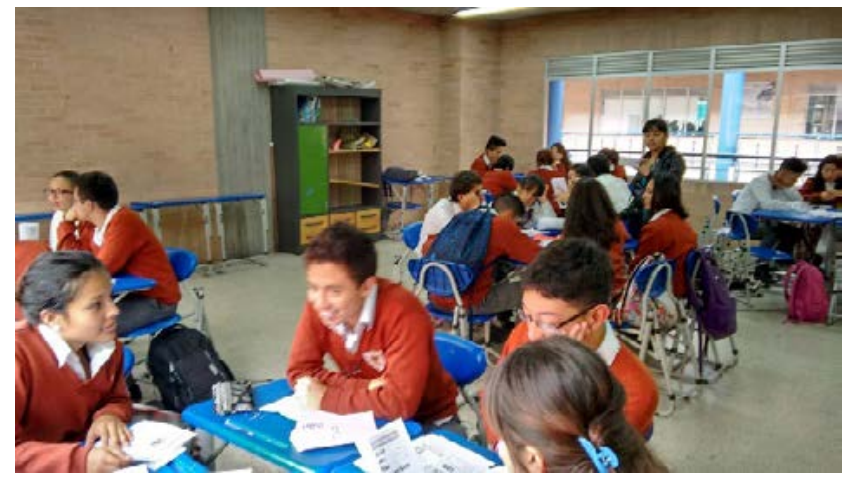

Figura 1. Mesa de expertos-socialización de lecturas

Fuente: fotografía de Jonatan Mora, Escuela Normal Superior Distrital María Montessori, 2015.

En la etapa de recreación, se experimentaron ritos de diferentes lugares del mundo y se vivenciaron las diversas sensibilidades que movilizan la espiritualidad del ser humano en diferentes culturas; la dinámica consistió entonces, en poner en 
escena los diferentes ritos seleccionados. Así, se notó que los estudiantes tuvieron la autonomía de lectura y de organización del rito que les correspondía por grupos, tenían que escoger desde su vestuario, hasta la forma de relacionar el rito con la obra literaria.

Realizaron verdaderas puestas en escena en donde se jugaba con elementos para la expresión oral y corporal, la capacidad para llamar la atención e integrar a sus pares en cada acción, todos laboraban para ampliar sus conocimientos y reconocer las actividades culturales y espirituales, que el hombre ha realizado a través del tiempo y que llamaron la atención de algunos escritores. Todos tomaron el té como las clases altas, mientras leían aquella escena de locos que protagoniza Alicia, más adelante se trasladaron a las canchas para coronar al mejor jugador olímpico, mientras comprendían cómo despedían a Patroclo en la Ilíada, luego recordaron en medio de fiesta y lágrimas a sus muertos en la purificación de las almas, mientras escuchaban a fondo el flamenco gitano de Lorca, se retaron por equipos en el Haka Maori antes de iniciar un duelo en el fútbol americano, mientras imitaban las historias de los cuentos y leyendas maorís y movieron lo más profundo del alma recitaron poemas mientras danzaban la mística música hindú.

Lo anterior con el fin de llegar a un taller significativo y lúdico, es decir las puestas en escena lograron que los estudiantes apropiaran en su parte cognitiva y subjetiva los contenidos de las historias, imaginaran nuevos mundos $y$, sobre todo, que experimentaran hechos que forman parte de la realidad y que se pueden relacionar con su contexto, así "los talleres tienden vínculos entre la vida cotidiana de los estudiantes y el conocimiento escolar, otorgándole nuevos sentidos a la educación" (Rodríguez, 2012, p. 23). Esta relación se reconoce por las acciones placenteras que generan en el individuo sus vivencias, no es lo mismo estar sentado en una clase de lengua castellana escuchando un cuento, que comprenderlo a través del juego del lenguaje, de la recreación, de la creatividad; oportunidad que el taller sí posibilita.

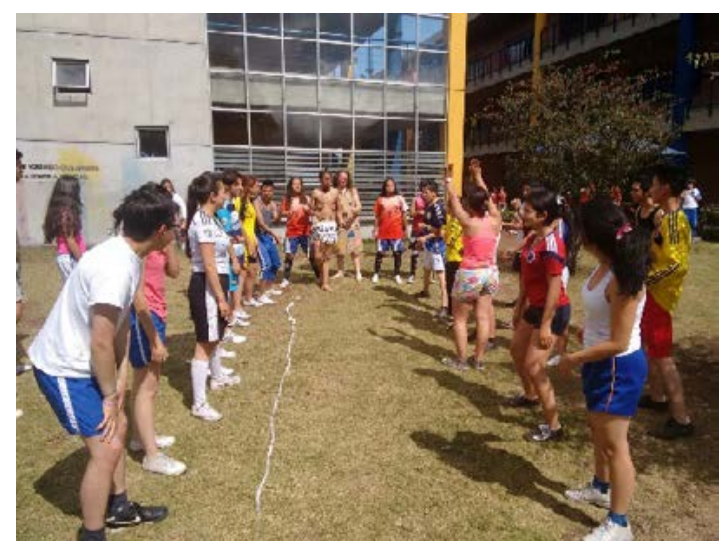

Figura 2. Puesta en escena (ritual "Haka Maori")

Fuente: fotografía de Jonatan Mora, Escuela Normal Superior Distrital María Montessori, 2015.

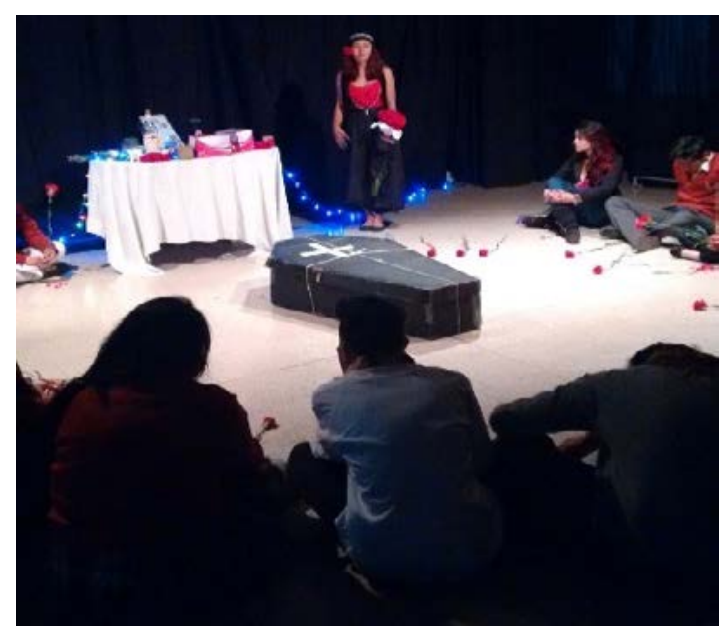

Figura 3. Puesta en escena (ritual "Día de los Muertos")

Fuente: fotografía de Jonatan Mora, Escuela Normal Superior Distrital María Montessori, 2015.

Por último, la etapa de reflexión permitió que cada estudiante después de haber vivido la experiencia de la puesta en escena del ritual, reflexionara en relación con la literatura; para ello, los estudiantes realizaron sus productos finales, con el fin de que se evidenciara individualmente la lectura consciente y la respectiva asociación y retroalimentación del taller. También, los docentes en formación pudieron cuestionar los resultados del 
proyecto y recogieron las vivencias que sirvieron para afirmar el gusto por su profesión. Así fue como lograron inspirar a cada participante para llevar a cabo sus productos finales según el proceso, entre otros: mapas conceptuales, reseñas literarias, caligramas, comentarios literarios, historietas, haikús, cuentos, mitos, debates, conversatorios, etc.

Se evidencia en esta última etapa al taller como puente interdisciplinario de integración, de creación, de motivación y de reflexión, pues a

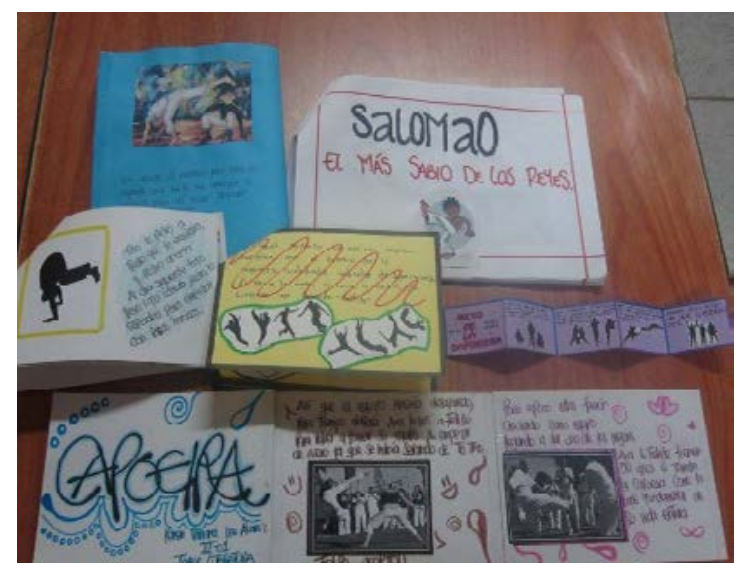

Figura 4. Producto: historietas del ritual "Capoeira"

Fuente: fotografía de Jonatan Mora, Escuela Normal Superior Distrital María Montessori, 2015.

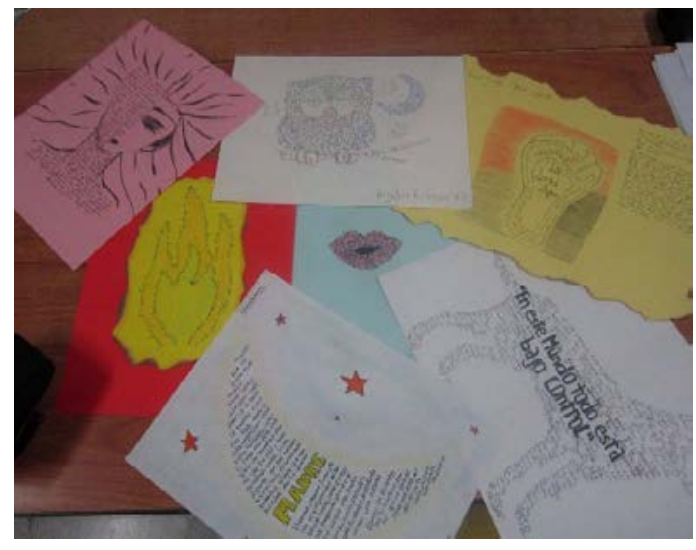

Figura 5. Producto: caligramas del ritual de la "danza hindú"

Fuente: fotografía de Jonatan Mora, Escuela Normal Superior Distrital María Montessori, 2015. través de la producción textual de cualquier tipología, el estudiante aprende haciendo, claro está, luego de haber adaptado su experiencia, lo que demuestra que su aprendizaje fue efectivo. No es cuestión de solo pedir tediosos ensayos en las clases de lengua castellana, cuando se puede explotar la creatividad de los educandos por medio de diferentes productos, que le Ilamaran más su atención y lo motivarán a ser un artesano más dentro del taller.

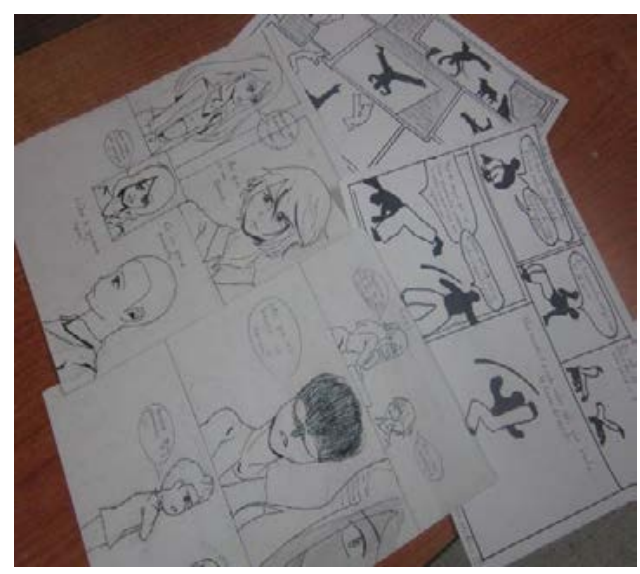

Figura 6. Producto: historietas del ritual "Capoeira"

Fuente: fotografía de Jonatan Mora, Escuela Normal Superior Distrital María Montessori, 2015.

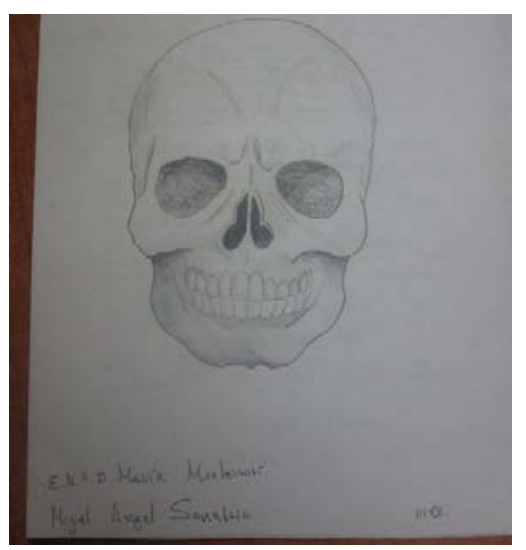

Figura 7. Producto: dibujo ritual "Día de los Muertos"

Fuente: fotografía de Jonatan Mora, Escuela Normal Superior Distrital María Montessori, 2015. 
En cuanto a la evaluación, el taller de literatura apartó todo cuestionario tedioso y en su lugar incorporó varias rejillas, las cuales contenían algunos criterios evaluativos según la actividad realizada en cada etapa (lecturas comentadas, discusiones, debates, cine foros, puestas en escena de los rituales, trabajo en grupo, etc.); estas rejillas eran diligenciadas por cada estudiante teniendo en cuenta la valoración cualitativa y cuantitativa de su desempeño, según sus docentes (heteroevaluación), sus compañeros (coevaluación) y según él mismo (autoevaluación). El mismo procedimiento se llevó a cabo con los productos escritos finales.

Según las rejillas de evaluación, cabe resaltar que los estudiantes fueron muy sinceros y autónomos a la hora de autoevaluarse o de evaluar a sus compañeros; así, especificaron algunos participantes que no habían colaborado con la preparación de cada ritual y la necesidad de escoger un líder para motivar y organizar al grupo. Claramente, al momento de realizar la puesta en escena, unos grupos se destacaron sobre otros, en especial a la hora de dinamizar, proponer o dirigir cada una de las acciones. Además, fue evidente el avance que se lograba desde la etapa de profundización, pues, al principio, los vacíos lectores eran bastantes, las relaciones entre los estudiantes eran muy sueltas y la expresión oral dejaba mucho que desear; por tanto, los primeros resultados que se obtenían eran de bajos desempeños, pero en la etapa de recreación y reflexión buscaron siempre obtener avances y más, a través de la motivación y la competencia, marcando así las casillas de "casi siempre" (4) y "siempre" (5).

El uso de rejillas de evaluación permite que el estudiante reconozca que, según su proceso y participación en el taller, va desarrollando varios criterios académicos, personales y de convivencia y no

Tabla 1. Rejilla de evaluación para la puesta en escena y desarrollo de cada ritual.

\begin{tabular}{|c|c|c|c|c|c|}
\hline \multirow[b]{2}{*}{ Criterios de evaluación } & \multicolumn{5}{|c|}{ Escala de evaluación } \\
\hline & $\stackrel{5}{5}$ & $\begin{array}{c}4 \\
\text { Casi } \\
\text { siempre }\end{array}$ & $\begin{array}{c}3 \\
\text { Algunas } \\
\text { veces }\end{array}$ & $\begin{array}{c}2 \\
\text { Pocas } \\
\text { veces }\end{array}$ & $\begin{array}{c}1 \\
\text { Nunca }\end{array}$ \\
\hline \multicolumn{6}{|l|}{ En relación con la preparación de los rituales } \\
\hline \multicolumn{6}{|l|}{$\begin{array}{l}\text { 1. ¿He consultado en distintas fuentes sobre el ritual seleccionado y he } \\
\text { leído de manera amplia y suficiente? }\end{array}$} \\
\hline \multicolumn{6}{|l|}{ 2. ¿He aprovechado tiempo de clase previsto para el ensayo del ritual? } \\
\hline \multicolumn{6}{|l|}{ 3. ¿He planeado con anticipación la puesta en escena del ritual? } \\
\hline \multicolumn{6}{|l|}{ 4. ¿He aportado en el diseño del material necesario para el ritual? } \\
\hline \multicolumn{6}{|l|}{ 5. ¿He participado en los ensayos previos al ritual? } \\
\hline \multicolumn{6}{|l|}{ 6. ¿He leído con anticipación la lectura literaria correspondiente al rito? } \\
\hline \multicolumn{6}{|l|}{ En relación con la puesta en escena del ritual } \\
\hline \multicolumn{6}{|l|}{$\begin{array}{l}\text { 7. ¿Inicie junto con mi grupo la presentación del ritual en los tiempos } \\
\text { acordados en clase? }\end{array}$} \\
\hline \multicolumn{6}{|l|}{ 8. ¿Participé en las orientaciones dadas a los participantes en el ritual? } \\
\hline \multicolumn{6}{|l|}{$\begin{array}{l}\text { 9. ¿Estimulé la interacción entre compañeros de mi grupo dinamizador } \\
\text { del rito y entre los participantes? }\end{array}$} \\
\hline \multicolumn{6}{|l|}{ 10. ¿Usé distintas estrategias de motivación al interior del grupo? } \\
\hline \multicolumn{6}{|l|}{$\begin{array}{l}\text { 11. ¿Logré aportar a la creación de un clima de confianza que facilita que } \\
\text { cada participante se exprese con libertad y sea escuchado con respeto? }\end{array}$} \\
\hline \multicolumn{6}{|l|}{$\begin{array}{l}\text { 12. ¿Aporté en el establecimiento de lazos de confianza y respeto entre } \\
\text { los participantes? }\end{array}$} \\
\hline 13. ¿Estuve atento a orientar y sortear los imprevistos? & & & & & \\
\hline
\end{tabular}

Fuente: Mora, Torres y Triana (2015). 
solo el hecho de tener conocimiento. De igual manera se elimina la posible arbitrariedad de que una sola persona califique cuantitativamente, sin antes revisar las habilidades o dificultades presentes en cada actividad. Entonces, cada participante con estos resultados identifica cuáles deben ser sus mejoras y los grandes alcances que puede llegar a tener.

En fin, tanto docentes en ejercicio como en formación, dejaron que entre todos se compararan y asociaran hechos de la realidad, a través de las lecturas realizadas y de la puesta en escena de cada ritual, fue una interacción dialógica entre todos los participantes, incluso entre los docentes que en un trabajo conjunto lograron hacer del taller de literatura un espacio en el que todos aprendieron y desarrollaron diversas capacidades cognitivas y personales.

\section{Conclusiones}

Abordando la ejecución del proyecto y su respectiva reflexión, se concluye en primera medida que quienes dirigen la planeación y desarrollo de las prácticas docentes en las diferentes facultades de educación de las instituciones, deben siempre brindar las herramientas para que los futuros maestros puedan a través de la reflexión, reconocer los avances y fallas que dirigen su profesión; herramientas que le permitan ser creador, participante, orador y guía. Teniendo en cuenta esta necesidad, el maestro en formación para la enseñanza de la literatura puede desarrollar sus capacidades dialógicas y discursivas en un espacio como el taller de literatura, donde interactúa de manera constante con sus primeros estudiantes y, por medio de la palabra, empieza a expresar sus conocimientos cognitivos y prácticos. Solo cuando reacciona ante las problemáticas educativas, puede ir reflexionando sobre los beneficios y los quiebres de lo que se ha hecho, a la vez, construye su labor y alimenta sus aprendizajes.

De esta manera, organizar y estructurar conjuntamente este tipo de talleres dentro del marco de un proyecto de aula, permitió reconocer que estas nuevas metodologías, ante la situación de varias instituciones educativas del país -donde las maneras de enseñanza se han caracterizado por trabajar el conocimiento a través de las asignaturas tradicionales- transforman el sistema educativo $y$, sobre todo, aumentan el conocimiento de los jóvenes.

Por tanto, tras esta experiencia y reflexión, no es atrevido afirmar que trascender de la asignatura al taller de literatura es una de las mejores alternativas para el desarrollo de la enseñanza y el fortalecimiento de las capacidades interpretativas y argumentativas de los estudiantes. Además, este trabajo planeado y realizado en equipo demuestra las maneras en que las prácticas de enseñanza de la literatura dentro de un escenario investigativo, se van potencializando gracias a que cada docente en formación en su acción y reflexión, desarroIla sus saberes cognitivos y, a la vez, sus saberes prácticos.

Tomar entonces el taller de literatura como estrategia didáctica y dialógica constituye ese espacio que fortalece las relaciones entre los participantes, ya que facilita el desarrollo de la capacidad oral y discursiva tanto de docentes como de estudiantes; es una actividad dinámica y no estática en la que en una serie de momentos (organizados y estudiados con anterioridad), entre todos, se va construyendo el conocimiento a través de la interacción y del trabajo conjunto, en donde el docente es un guía y el estudiante es un artesano.

En suma, haber realizado este proyecto demuestra que dentro de un escenario educativo se debe innovar, se deben generar ambientes que despierten el interés y el dinamismo, pues en este caso, la literatura permite que así sea y que dentro de varios talleres se persiga en últimas el objetivo final: construir un currículo que incluya las necesidades de la escuela y del contexto en el que se desarrollan los saberes, sin olvidar que este es una construcción cultural y social que solo le compete a los que participan en la educación. Entonces, el taller de literatura como estrategia didáctica y dialógica requiere comprender el lugar del taller en la escuela, la comprensión conceptual y funcional 
del currículo en este tipo de estrategias y cómo el docente en formación, dentro de su práctica, puede ser agente investigativo en la escuela con su propio actuar y pensar a través de la interacción y la reflexión.

\section{Reconocimientos}

Este artículo evidencia los resultados obtenidos en el proyecto "Ritos y rituales, un viaje por el mundo a través de la literatura universal", desarrollado en la Escuela Normal Superior Distrital María Montessori (ENSDMM) de Bogotá D.C., con estudiantes de grado undécimo dentro del espacio "Taller de literatura II" en el año 2015. En este participaron estudiantes en formación de la Universidad Distrital Francisco José de Caldas, como Ángel Jonatan Mora Ramírez, María Fernanda Torres y Yesny Milena Triana, quienes se encontraban realizando la práctica docente exigida en octavo y noveno semestre de la carrera, dirigidos y acompañados por la docente titular Mirta Yolima Gutiérrez Ríos y la docente de práctica Gloria Rojas Álvarez.

\section{Referencias bibliográficas}

Bajtín, M. (1982). Estética de la creación verbal. México: Siglo XXI.

Congreso de Colombia (8 de febrero de 1994). Ley 115 de 1994. Ley General de Educación. DO: 41.214. Recuperado de http://www.mineducacion.gov. co/1621/articles-85906_archivo_pdf.pdf

Guevara, C. (ed.). (2015). Enseñanza de la literatura: perspectivas contemporáneas. Bogotá: Universidad Distrital Francisco José de Caldas.
Gutiérrez, M. (15 de agosto de 2016). Formar docentes para el diálogo crítico y creativo (parte 1). Compartir palabra maestra. Recuperado de https:// compartirpalabramaestra.org/columnas/formar-docentes-para-el-dialogo-critico-y-creativo-parte-1

Grundy, S. (1994). Producto o praxis del curriculum. Madrid: Ediciones Morata, S.L.

Lewis, C. (1865). Alicia en el país de las maravillas. Recuperado de http://portales.puj.edu.co/ftpcentroescritura/Recursos/Normasapa.pdf

Masgrau, M. y Falgas, M. (2013). ¿Cómo lo hago en clase? Una mirada a la acción didáctica desde la autoconfrontación y la reflexión para la formación inicial de maestras. Ikastaria, 19, 97-137.

Ministerio de Educación Nacional (MEN) (2014). Lineamientos Curriculares de Lengua Castellana. Recuperado de: https://www.mineducacion.gov. co/1621/articles-339975_recurso_6.pdf.

Mora, J., Torres, M. y Triana, Y. (2015). Ritos y rituales, un viaje por el mundo a través de la literatura universal. Bogotá: Escuela Normal Superior Distrital María Montessori.

Paz, O. (1950). Todos santos, día de muertos. En El laberinto de la soledad (pp.18-26). México: Fondo de Cultura Económica.

Segalen, M. (2005). Ritos y rituales contemporáneos. Madrid: Alianza Editorial, S.A.

Rodríguez, M.E. (2012). El taller: una estrategia para aprender, enseñar e investigar. En: S. Soler (ed.). Lenguaje y educación: perspectivas metodológicas y teóricas para su estudio (pp. 13-43). Bogotá, Colombia: Comité Editorial-CADE.

Vásquez, F. (2006). La enseña literaria. Crítica y didáctica de la literatura. Bogotá: Mancha de Voces. 